\title{
Using polypropylene mesh graft for soft-tissue reconstruction in internal hemipelvectomy: a case report
}

\author{
Apichat Asavamongkolkul and Saranatra Waikakul
}

\begin{abstract}
We report the case of a patient with chondrosarcoma involving the right pelvis and contralateral pubic area in a 45-year-old male who underwent an extensive internal hemipelvectomy without bony reconstruction. We demonstrate the technique of using polypropylene mesh graft for soft-tissue reconstruction. Follow-up at 7.5 years showed a good oncological and functional outcome.
\end{abstract}

Keywords: Internal hemipelvectomy, Chondrosarcoma, Malignant tumor, Pelvis, Polypropylene mesh graft

\section{Background}

Pelvic tumors have previously been treated with standard hemipelvectomy, that is, hindquarter amputation [1]. Nowadays, advances in adjuvant chemotherapy, radiation therapy, imaging and surgical techniques have allowed more patients to be treated with limb salvage surgery and have better survival rate and quality of life. However, limb salvage around the periacetabular area following malignant tumor removal is one of the most challenging procedures in musculoskeletal oncology. Because of large tumor size and the complexity of anatomy in this location, resections of tumor are mostly difficult and reconstructions are demanding procedures in this area. Recent reconstructive options for limb salvage around the periacetabular area include vascularized autografts; nonvascularized autografts; autoclaved, resected, or microwave-induced hyperthermia of bone from the same pelvis; massive pelvic allograft; endoprosthesis; resection arthrodesis; local improvised reconstruction with plates, pins and screws augmented with bone cement; and no reconstruction (internal hemipelvectomy) [2-16]. The average functional results following limb salvage in this particular area are fair and the complications for each reconstruction are not uncommon. We report the results of a patient with chondrosarcoma involving the whole pelvis and with contralateral

\footnotetext{
* Correspondence: siaas@mahidol.ac.th

Department of Orthopaedic Surgery, Faculty of Medicine, Siriraj Hospital, Mahidol University, 2 Prannok Road, Bangkok 10700, Thailand
}

involvement of the pubis, who was treated by an internal hemipelvectomy and by using polypropylene mesh graft for augmentation and reconstruction of muscles around the pelvis.

\section{Case presentation}

A 45-year-old Thai male presented with a six-month history of right buttock and hip pain. The patient could not recall any injuries or incidents that may have caused the pain. He had no medical problems nor was he taking any medication. The MRI of the lumbosacral spine from the initial consultation at another hospital was unremarkable. He was treated unsuccessfully with a nonsteroid anti-inflammatory drug and acetaminophen. He was referred to our institution for consultation. Physical examination revealed a healthy-appearing adult with an ill-defined $12 \mathrm{~cm} \times 20 \mathrm{~cm}$ nontender firm mass at frank and groin area. There was no overlying skin change. Both hips had a full range of movement. The neurovascular function in the field of lower extremity was found to be intact, except the power of extensor hallucis longus on the right side was grade $4 / 5$. He had no palpable lymphadenopathy. Laboratory studies were within normal limits.

A plain radiograph of the pelvis revealed a welldefined mineralized mass extending from the right pubic and periacetabular area that also extended to the left pubic bone. The right obturator foramen was obliterated by the tumor mass. There was a popcorn-like chondroid 
matrix at the soft-tissue part of the tumor, which also extended into the pelvic cavity (Figure 1). Bone scintigraphy and computed tomography (CT) of the chest showed no distant metastasis except the abnormal uptake of the right pelvic and hip area. The CT scan of the pelvis showed a huge tumor mass in the pelvic cavity that involved the right sacroiliac joint and anterior border of the sacrum (Figure 2). The initial diagnosis was a chondrosarcoma involving both pubic areas, the right periacetabulum and ilium.

Incisional biopsy was performed over the right pubic area. Microscopic examination revealed small chondrocytes with dark nuclei and scant cytoplasm. They were arranged in clones and binucleated cells were present. No mitotic figures were found. The diagnosis was consistent with chondrosarcoma. The tumor was classified as Grade I (well-differentiated) (Figure 3) according to the musculoskeletal tumor society staging system [17]. In this patient, the tumor resection was at PI-II-III, according to the Ennecking and Dunham classification [18] for the resection of primary tumor involving the pelvic bone. An internal hemipelvectomy with wide margin tumor removal was performed in this patient using the modified technique described by Eilber et al. [12]. The incision was made from left inguinal area to right pubis and anterior superior iliac spine, then curved superoposterior to iliac crest. The previous biopsy scar was ellipsed out from the incision. The external iliac vessels, femoral and sciatic nerves were preserved and mobilized from the tumor. The muscles attached to the pelvic bone were dissected out from the affected pelvis such as rectus abdominis, abdominal muscles, iliacus, gluteal muscles, rectus femoris, adductors and hamstrings. Osteotomies were made through the sacral ala just lateral to the neural foramina and contralateral

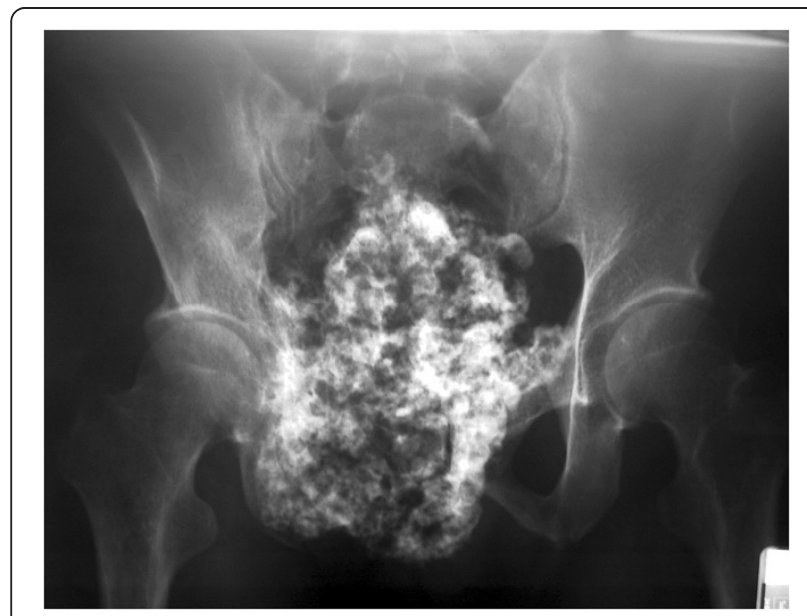

Figure 1 Anteroposterior radiograph of the pelvis showing chondrosarcoma is located at the right pubis and periacetabulum and extends to the left pubic area.

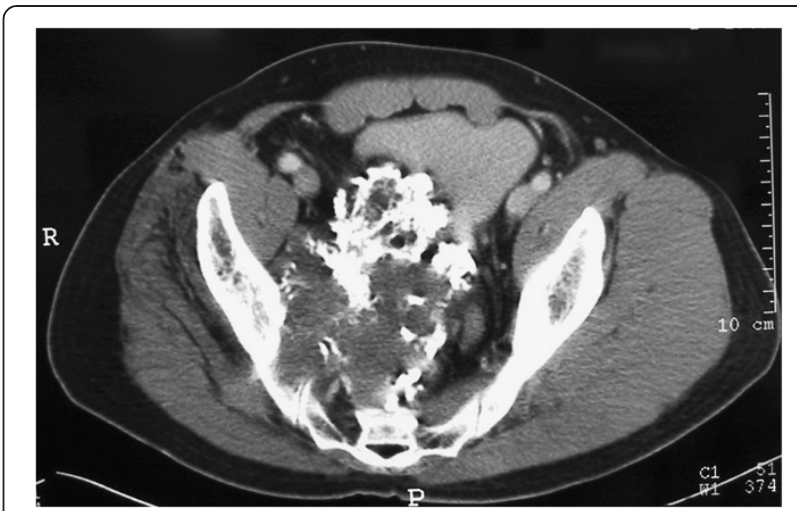

Figure 2 CT scan of the pelvis showing the tumor sized $12 \mathrm{~cm} \times 10 \mathrm{~cm}$ originates from the right pelvis and invades the sacroiliac joint and pelvic cavity.

pubic rami and ischium. A polypropylene mesh (Parietene, Sofradim, Trevoux, France) was used as an anchoring mesh to maintain all dissected muscle from the pelvis and soft-tissue reconstruction (Figure 4-5). All muscles were sutured along with mesh by prolene no. 0 . They were kept attached with mesh at their optimal anatomical length to gain maximal muscle strength. Gluteal, lumbosacral and hamstrings were firstly sutured behind the mesh. Then, abdominal muscles, rectus abdominis, rectus femoris and adductor were sutured respectively by their anatomical layers. The final pathological report confirmed a well-differentiated chondrosarcoma with free margin. The radiograph of the pelvis following an internal hemipelvectomy showed upward migration of the head of the right femur (Figure 6).

Patient was placed in balanced skeletal traction at the tibial tuberosity with a weight of fifteen pounds for three weeks after surgery. Rehabilitation was uneventful. Progressive partial weight-bearing with axillary crutches was

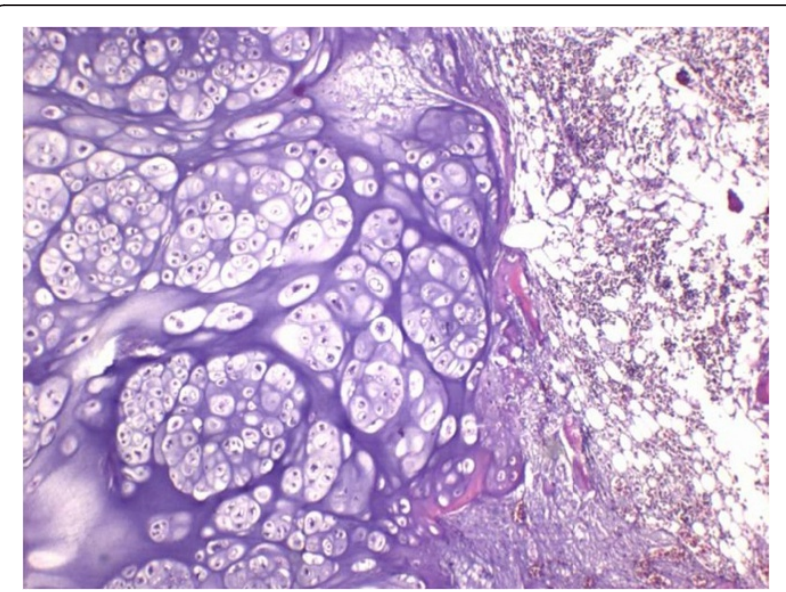

Figure 3 A photograph of the microscopic examination of the well-differentiated chondrosarcoma. 


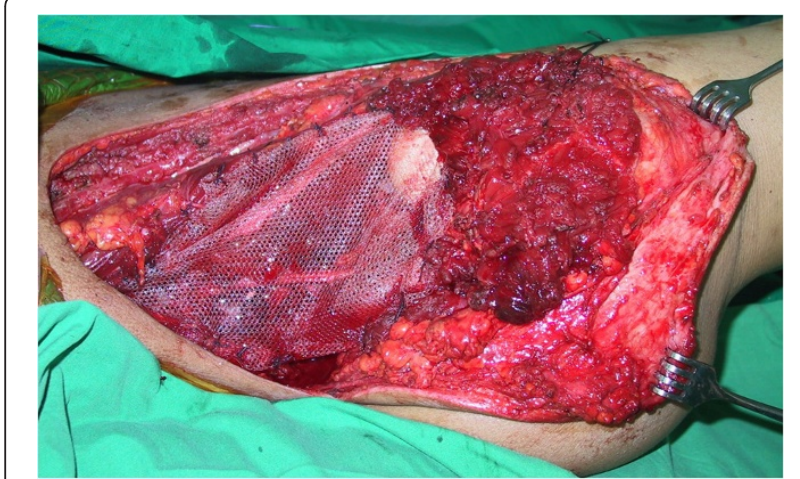

Figure 4 An intraoperative photograph of the internal hemipelvectomy. All dissected abdominal, back and gluteal muscles are sutured to the mesh.

allowed after six to eight weeks. Regular strengthening exercises of the psoas, gluteus, quadriceps, and hamstring muscles were started and maintained to the highest level of tolerance during this period. At 7.5-year follow-up, the patient remained disease-free without local or distant relapse of the disease. No infection or wound complication occurred in this patient. Partial peroneal nerve palsy occurred, but was improved at the last visit. The patient had regained a range of motion of hip abduction of $15^{\circ}$ and a range of hip flexion of $15^{\circ}$. The functional analysis at the final follow-up according to the Musculoskeletal Tumor Society system [19] was $66.7 \%$. He had a $3 \mathrm{~cm}$ leg-length discrepancy, which could be compensated by simple shoe lifts. He was able to perform most activities of daily living without any

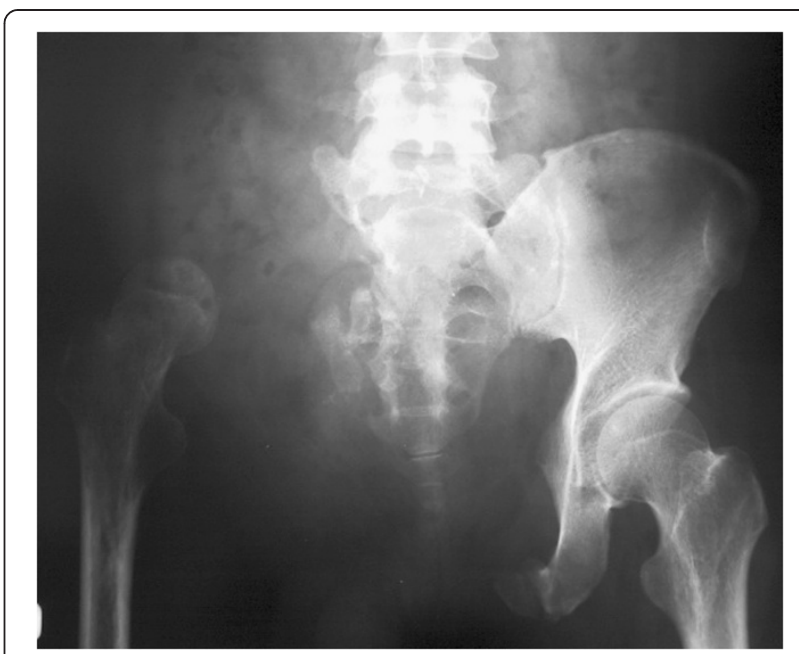

Figure 6 Anteroposterior radiograph of the pelvis postinternal hemipelvectomy showing an upward migration of the head of the right femur and tumor margin extending through the right sacral foramens.

assistance. He could resume his employment as an electrical engineer by using one Canadian crutch during walking and could participate in sports exercise such as swimming or bicycling (Figure 7).

\section{Discussions}

Primary malignant bone tumors involving the pelvis account for $15 \%$ of all primary malignant bone tumors [1]. The goal of treating primary malignant bone tumors has expanded to both cure disease and provide a good

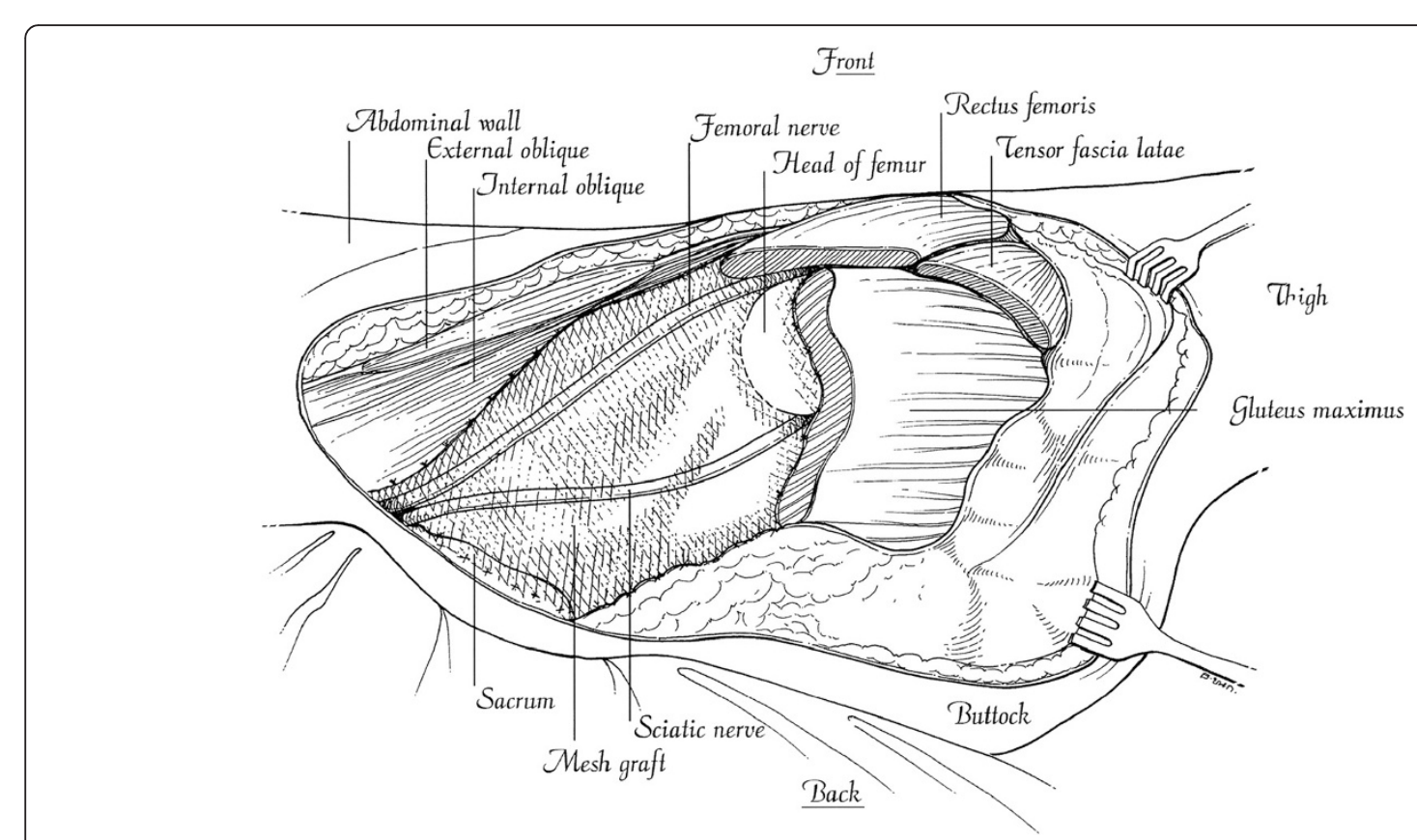

Figure $5 \mathrm{~A}$ drawing showing the intraoperative reconstruction of the patient. 


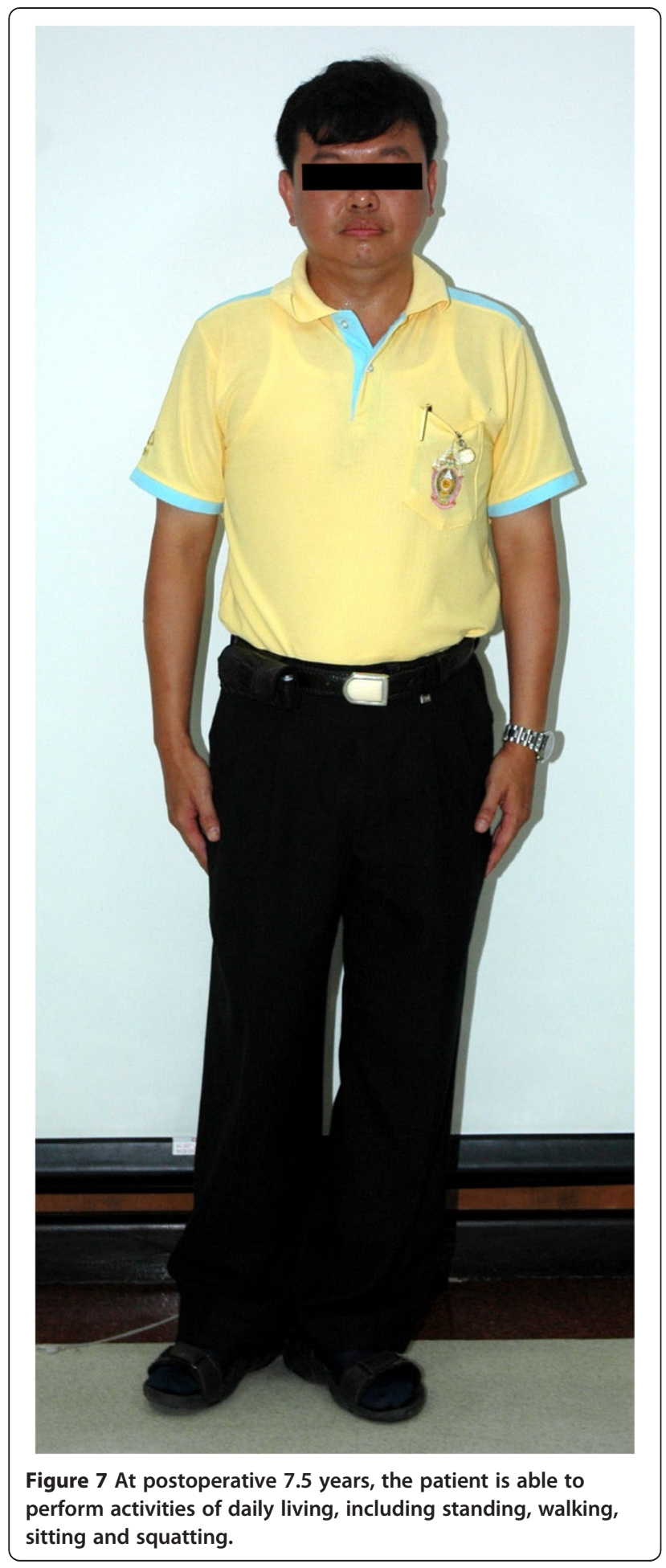

quality of life. Tumors of the periacetabulum are amenable to curative intent but require wide or radical margins. Inadequate tumor surgical margin has a high risk of local recurrence and a poor prognosis for the patient. Classic hemipelvectomy is a common procedure for the removal of large tumors in the location that cannot be removed by limb salvage surgery with an adequate margin [4]. The rate of local recurrence was reported from 23 to $30 \%[14,15,20,21]$. This patient had an internal hemipelvectomy with a wide margin of tumor removal. Clear resection margin is the goal for chondrosarcoma, as there seems to be no convincing adjuvant treatment modality to prevent local recurrence in the event of tumor contamination. He remained disease-free without disease relapse at 7.5-year follow-up.

Several options for pelvic and periacetabular reconstruction after internal hemipelvectomy have been reported using vascularized autografts; nonvascularized autografts; autoclaved, resected, or microwave-induced hyperthermia of bone from the same pelvis; massive pelvic allograft; endoprosthesis; resection arthrodesis; local improvised reconstruction with plates, pins and screws augmented with bone cement; and no reconstruction (internal hemipelvectomy) [2-16]. Most reconstructive options for limb salvage in periacetabulum are associated with a high rate of complications and morbidity. The high complication rate is attributed to extensive bone loss and durability of the implant. The complications include deep infection, wound skin necrosis, and implant loosening. The rate of adjunctive surgery is high for the patients with such a complication [22,23]. Some patients even require implant or allograft removal that can result in a flail hip. Even a classic hemipelvectomy is determined in the final analysis for treating the complications. Several series demonstrated that internal hemipelvectomy without reconstruction in selective patients could provide fewer complications, acceptable function and cost-effectiveness of treatment $[12,15,24]$.

For internal hemipelvectomy without reconstruction, surrounding muscles and soft tissue have been dissected from the resected pelvic bone tumor and need to be repaired and reconstructed to maintain the optimal function of the hip and leg for the patient. We used a Parietene polypropylene mesh (Parietene, Sofradim, Trevoux, France) as an anchoring material to reapproximate all the muscles that attach to the pelvis. All muscles including abdominal, gluteal, psoas, rectus femoris and hamstrings must be sewed back with a good anatomical length to gain optimal function [15]. With this technique and an optimal physical therapy program, the patient could gain acceptable function of the affected hip and leg and he could resume his previous profession. Asavamongkolkul et al. and Schwartz et al. demonstrated that patients with primary malignant bone tumor around the pelvic region had fair to good function with acceptable complication rates after tumor excision without reconstruction $[15,16]$. The patient in this report experienced a $3 \mathrm{~cm}$ leg-length discrepancy, he could compensate for by simple shoe lifting. He could resume 
his gainful employment and also enjoyed some sporting activities.

\section{Conclusions}

Using polypropylene mesh graft for soft-tissue reconstruction in internal hemipelvectomy following malignant tumor removal is an alternative reconstruction in selected cases of pelvic malignant tumor. Patients undergoing this type of reconstruction, according to our prior experiences and from literature, can benefit from fewer complications with acceptable function.

\section{Consent}

Written informed consent was obtained from the patient for publication of this case report and the accompanying images. Copies of the written consent form are available for review upon request.

\section{Competing interests}

The authors declare that they have no competing interests.

\section{Acknowledgements and funding}

None

\section{Authors' contributions}

AA composed the case report, prepared and edited this manuscript, contributed it conception, collected the data and conducted a literature search. SW participated in the data collection and gave final approval for this version of the manuscript. All authors read and approved the final manuscript.

Received: 9 February 2012 Accepted: 28 June 2012

Published: 28 June 2012

\section{References}

1. Miller TR: 100 cases of hemipelvectomy: a personal experience. Surg Clin North Am 1974, 54:905-913.

2. Hubert DM, Low DW, Serletti JM, Chang B, Dormans JP: Fibula free flap reconstruction of the pelvis in children after limb-sparing internal hemipelvectomy for bone sarcoma. Plast Reconstr Surg 2010, 125:195-200.

3. Akiyama T, Clark JC, Miki Y, Choong PF: The non-vascularised fibular graft: a simple and successful method of reconstruction of the pelvic ring after internal hemipelvectomy. J Bone Joint Surg Br 2010, 92:999-1005.

4. Harrington KD: The use of hemipelvic allografts or autoclaved grafts for reconstruction after wide resections of malignant tumors of the pelvis. $J$ Bone Joint Surg Am 1992, 74:331-341.

5. Satcher RL Jr, O'Donnell RJ, Johnston JO: Reconstruction of the pelvis after resection of tumors about the acetabulum. Clin Orthop Relat Res 2003, 409:209-217.

6. Fan QY, Ma BA, Zhou Y, Zhang MH, Hao XB: Bone tumors of the extremities of pelvis treated by microwave-induced hyperthermia. Clin Orthop Relat Res 2003, 406:165-175.

7. Mnaymneh W, Malinin T, Mnaymneh LG, Robinson D: Pelvic allograft. A case report with a follow-up evaluation of 5.5 years. Clin Orthop Relat Res 1990, 255:128-132

8. Bruns J, Luessenhop SL, Dahmen G Sr: Internal hemipelvectomy and endoprosthetic pelvic replacement: long-term follow-up results. Arch Orthop Trauma Surg 1997, 116:27-31.

9. Sun W, Li J, Li Q, Li G, Cai Z: Clinical effectiveness of hemipelvic reconstruction using computer-aided custom-made prostheses after resection of malignant pelvic tumors. J Arthroplasty 2011, 26:1508-1513.

10. Muller PE, Durr HR, Wegener B, Pellengahr C, Refior HJ, Jansson V: Internal hemipelvectomy and reconstruction with a megaprosthesis. Int Orthop 2002, 26:76-79.

11. Renard AJ, Veth RP, Schreuder HW, Pruszczynski M, Keller A, van Hoesel Q Bokkerink JP: The saddle prosthesis in pelvic primary and secondary musculoskeletal tumors: functional results at several postoperative intervals. Arch Orthop Trauma Surg 2000, 120:188-194.

12. Eilber FR, Grant TT, Sakai D, Morton DL: Internal hemipelvectomy-excision of the hemipelvis with limb preservation. An alternative to hemipelvectomy. Cancer 1979, 43:806-809.

13. Steel HH: Partial or complete resection of the hemipelvis. An alternative to hindquarter amputation for periacetabular chondrosarcoma of the pelvis. J Bone Joint Surg Am 1978, 60:719-730.

14. Enneking WF, Dunham WK: Resection and reconstruction for primary neoplasms involving the innominate bone. J Bone Joint Surg Am 1978, 60:731-746.

15. Asavamongkolkul A, Pimolsanti R, Waikakul S, Kiatisevi P: Periacetabular limb salvage for malignant bone tumours. J Orthop Surg 2005, 13:273-279

16. Schwartz AJ, Kiatisevi P, Eilber FC, Eilber FR, Eckardt JJ: The Friedman-Eilber resection arthroplasty of the pelvis. Clin Orthop Relat Res 2009, 467:28252830.

17. Enneking WF, Spanier SS, Goodman MA: A system for the surgical staging of musculoskeletal sarcoma. Clin Orthop Relat Res 1980, 286:241-246.

18. Enneking W, Dunham W, Gebhardt M, Malawar M, Pritchard D: A system for the classification of skeletal resections. Chir Organi Mov 1990, 1:S217-S240.

19. Enneking WF, Dunham W, Gebhardt MC, Malawar M, Pritchard DJ: A system for the function evaluation of reconstructive procedures after surgical treatment of tumors of the musculoskeletal system. Clin Orthop Relat Res 1993, 286:241-246.

20. Guest CB, Bell RS, Davis A, Langer F, Ling H, Gross AE, Czitrom A: Allograftimplant composite reconstruction following periacetabular sarcoma resection. J Arthroplasty 1990, 5:S25-S34.

21. O'Connor MI, Sim FH: Salvage of the limb in the treatment of malignant pelvic tumors. J Bone Joint Surg Am 1989, 71:481-494.

22. Stephenson RB, Kaufer H, Mankin FM: Partial pelvic resection as an alternative to hindquarter amputation for skeletal neoplasms. Clin Orthop Relat Res 1989, 242:1401-1406.

23. Abudu A, Grimer RJ, Cannon SR, Carter SR, Sneath RS: Reconstruction of the hemipelvis after the excision of malignant tumours. Complications and functional outcome of prostheses. J Bone Joint Surg Br 1997 79:773-779.

24. Bruns J, Luessenhop S, Behrens P: Cost analysis of three different surgical procedures for treatment of a pelvic tumour. Langenbecks Arch Surg 1998, 383:359-363.

doi:10.1186/1477-7819-10-124

Cite this article as: Asavamongkolkul and Waikakul: Using polypropylene mesh graft for soft-tissue reconstruction in internal hemipelvectomy: a case report. World Journal of Surgical Oncology 2012 10:124.

\section{Submit your next manuscript to BioMed Central and take full advantage of:}

- Convenient online submission

- Thorough peer review

- No space constraints or color figure charges

- Immediate publication on acceptance

- Inclusion in PubMed, CAS, Scopus and Google Scholar

- Research which is freely available for redistribution 